Helena Rodríguez Somolinos

\title{
What does ह̇iा really mean? Contact and dimensionality of the landmark as basic semantic categories in the locative prepositional phrases with ह̇mí
}

\begin{abstract}
The spatial relations expressed by the preposition ć $\pi$ í can be clarified attending to the dimensionality of the landmark as a basic semantic category, along with the constant notion of contact, belonging to the preposition. On the contrary, the orientation - from which the traditional explanations are derived is important but clearly secondary. After explaining the coexistence and partial synonymy of '̇ंí with dat. and gen. starting from the uses with three-dimensional landmarks, the study of the uses with two- and one-dimensional landmarks allows reformulation of the basic meaning of the preposition. In turn, this allows recognition of a system based on a very particular conceptual view about limits and ends in the different dimensions, a conceptual view in decline since Homer, although we can find other traces of it here and there, also in Latin.
\end{abstract}

Keywords: Greek prepositions; દ̇лí; locative meanings; dimensionality; limits and extremes; visual conceptualization; Latin ob, ad, extremus, exter, exterior.

Helena Rodríguez Somolinos: Instituto de Lenguas y Culturas del Mediterráneo y Oriente Próximo, CSIC, Madrid.E-mail: helena.rsomolinos@cchs.csic.es

\section{Introduction}

\subsection{The preposition émi and the DGE: the locative uses}

The understanding of the meanings and uses of the preposition $\dot{\varepsilon} \pi$ í continues posing a real challenge, despite the bibliography dedicated to the subject in the last hundred and fifty years. 'Erí is semantically a very complex preposition, broadly used with the three cases in all the ages. The main polysemy and complexity is without doubt in the uses with dative case, the most widely used and also the most difficult to understand, especially the local and abstract uses. On the other hand, there are different meanings that are expressed both with $\varepsilon \pi i$ + 
dat. and with غ̇ंí + gen.; not only local meanings, but also temporal and abstract ones. That is to say, there are broad areas of synonymy between both cases. This synonymy, on the one hand, and the locative use of the genitive, which in the words of Ruijgh (1994: 144) “est aberrant et pose un problème," on the other, constitute its principal anomalies.

It has been a long search for an original local meaning of '̇ंi and for the keys that allow an explanation of the rest of the local meanings deriving from it, as well as the coexistence of these broad areas of synonymy between the dative and the genitive. The general studies on Greek prepositions usually simplify the information and tend to reduce their modern equivalents especially to 'on' (Fr. sur, Ger. auf, Sp. sobre, etc.) and to a much lesser extent to the meaning 'close to', 'next to', considering it secondary and of limited use. The general dictionaries have not helped either, and the consequence is that very often modern scholars and translators do not have a clear idea of what type of spatial localization ' indicates, beyond the basic idea that the genitive means 'on', 'on top of', and that it usually implies contact. However, in many contexts we are forced to translate it in other ways, without knowing very well why, or we simply do not understand where the trajector really is with respect to the landmark, that is, which is the relation between them that is supposedly clarified by the prepositional phrase (PP).

The writing of the entry '̇ंí for the Volume VIII of the Diccionario GriegoEspañol (DGE) has forced us to study a huge volume of data from Homer up to 600 A.D., which has led us to reconsider these and other questions not sufficiently clarified in the bibliography. Apart from offering a better and clearer general organization of the meanings of $\dot{\varepsilon} \pi$ í than the previous general dictionaries, better establishing oppositions and meanings, we believe to have improved especially the understanding of the locative uses with the dative, which constitute the core of the preposition. In turn, the understanding of the locative uses with the genitive depends directly on this. Naturally, all the conclusions are equally valid for the adverbial and preverbial use of $\dot{\varepsilon} \pi i$, which has also benefitted the corresponding sections of the $D G E$.

In the clarification of the locative meanings, the conclusions reached from the analysis of hundreds of passages of Greek literature find solid support on certain ideas coming from cognitive linguistics, which has largely dealt in recent decades with the study of the spatial categories that enter into play in the prepositional constructions. Elements that have been revealed as determining factors in understanding the local uses of '́rí, at least up to the classical period, constitute important semantic categories in the modern theory on spatial analysis, and this in turn helps to confirm the ideas arising from the information itself in the process of editing the DGE. Therefore, we will make use of certain concepts and terms coming from this theoretical area, beginning with the terms trajector and 
landmark, which I will use for convenience. To the bibliography on the spatial relations expressed by means of prepositional phrases, both general and in reference to modern languages, some works must be added on ancient Greek, which incorporate the contributions of cognitive linguistics in a specially suitable field, as aforementioned. In particular there is the well-known book of Luraghi (2003), which has the virtue of not presenting an excessive theoretical discussion and of analyzing the prepositions in sufficient detail, although in the case of $\dot{\varepsilon} \pi$ í her conclusions do not always coincide with ours.

The traditional idea, well reflected in Luraghi (2003), is that the basic meaning of ' $\dot{\pi}$ ' is 'on top of', typical of the construction with the genitive, which sometimes turns into 'close to', and it is not possible to explain why. It is admitted that there is usually contact but sometimes there is not. And, as not all of this is conveniently explained, the conclusion is usually reached that '́r í indicates in many cases a vague localization around the landmark.

\subsection{Semantic categories and prepositional phrases}

The theoretical literature offers a series of tools for establishing the semantic categories and the linguistic or contextual elements that take part in the spatial relation expressed by means of a PP. Along with the general spatial categories (locativity, allativity/ablativity, perlativity), it has been traditionally established that other elements such as the type of verb (state, movement, action, etc.) and other semantic properties of the trajector and especially of the landmark along with the basic meaning of the preposition, become fundamental in determining the meaning of a PP.

In this field, perhaps the most valuable contribution of cognitive linguistics consists in paying attention to other elements of the spatial situation expressed in a PP which had not been taken into account before. I refer, in particular, to the properties of the objects in relation to space: features such as their shape, their size and their dimensions, and to information such as the presence or absence of contact or support between them, the distance between them, the orientation, etc. So, the elements that take part in the spatial configuration expressed in a locative expression, which according to Talmy (1983) reach the number of nineteen, have been analyzed in detail. The starting point is the division of a spatial configuration into figure (= trajector) and ground (= landmark); several of the remaining elements correspond to the geometry of one or the other, which the recipient usually knows (basic geometry of the figure, ditto for the ground, symmetrical or slanted geometry based on the parts of an object or its directionality, number of relevant dimensions in the geometry of figure and ground, conditions 
of the limits of each, continuous or composite geometry of both). Others correspond to the relative position of one or the other (orientation of the figure with respect to the ground, distance/magnitude of the figure in comparison with the ground, etc.). Others, finally, correspond to external elements, especially the point of view from which the configuration is considered, that is, the point of view of the speaker, which can also change.

Traditionally in the study of Greek prepositions these types of circumstances of the spatial situation have scarcely been taken into account, with the exception of the possibility or impossibility for the landmark to house the trajector inside it (landmark container). And of course, the orientation with respect to the vertical and horizontal axes - in relation to the surface of the ground - which is basic for our orientation and for spatial descriptions, is ineluctable in the case of ćrí, ưró, and ưrés.

Luraghi (2003: 25s., 247ss.) also points out the relevance in Homer of the semantic category that we have just mentioned as "continuous or composite geometry" of the landmark, although it is usually mentioned as plexity, according to the terminology of Talmy (2000). This category refers to the internal structure of the landmark, depending on whether it is discontinuous or continuous (multiplex/uniplex). According to Luraghi, along with the triple ablative/locative/allative opposition, corresponding to the genitive/dative/accusative use, a second system coexists based on plexity, which sometimes conditions the use of the genitive or the accusative with some prepositions such as $\mu \varepsilon \tau$. opposition is inherited from Indo-European, the second begins later, and is lost after Homer. The case has some interest because it highlights the importance of a physical feature of the landmark in order to determine the choice of the case and the meaning of the PP. In the case of ' $\pi^{\prime \prime}$, the internal structure of the landmark is irrelevant for Luraghi; on the contrary, she recognizes that, in order to understand its meaning, the really important notions are the contact and the verticality, that is to say, its orientation.

In opposition to previous trends, cognitive linguistics thinks that each preposition has an "ideal meaning," often called a "semantic prototype," which is present in each use of the preposition, and which corresponds to an abstract geometric idea. All the uses of the preposition are derived from it by means of diverse adaptations and transformations, which make the preposition appropriate in a wide variety of contexts (see for example, Herskovits 1986: 55ss.) In the case of the preposition $\varepsilon \pi$ í, we agree with Luraghi and other authors in the idea that contact is the main and constant notion that the preposition '́ $\pi$ í expresses in any of the spatial situations that it represents. The orientation constitutes an important, although, as we will see, secondary element. 


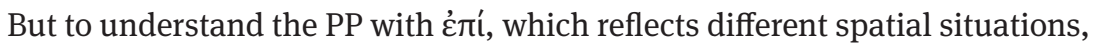
at least up to the classical period we believe that it is essential to turn also to one of the elements that according to Talmy take part in the spatial configuration expressed in a locative expression, and that we have quickly listed. We refer to the dimensionality of the landmark, that is, if it has one, two, or three dimensions according to traditional Euclidean geometry, which conceives a line as one-dimensional (1D), a surface as two-dimensional (2D), and a volume as three-dimensional (3D). Naturally, the dimensionality of an object depends directly on its shape and its size, but this datum is not quite as objective as it might seem. In its linguistic reflection, dimensionality is very often the result of a visual conceptualization that forms part of the process of geometric idealization that is produced in the spatial relations and in the objects that take part in them. Geometric idealization is an essential phenomenon in the process of adaptation to the language resources of the possible number of spatial relations between objects in the real world. But it forms part of the conventions of the language, since the same physical objects can be idealized in different ways in different languages. We will return to this when we speak of the one-dimensional landmarks.

The dimensionality of the landmark usually appears in the analysis of some modern prepositions. For example, the meaning of the French prepositions dans and sur has been related to it, an idea that has been well accepted by English-speaking linguists, repeatedly applying it to the semantic study of at, on, and in, sometimes called “dimensional prepositions” (Vandeloise 1991: 157s.; Radden and Dirven 2007: 309ss.)

In the case of Greek, the dimensionality of the landmark has never been taken into account, because it is not an element that creates oppositions between prepositions, nor does it have any degree of grammaticalization. However, it has been found to be a key element in order to understand the locative meanings of

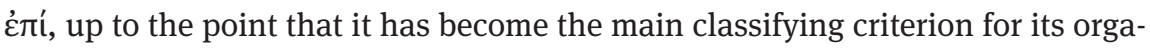
nization in the entry غ́лi of the DGE. This datum does not form part of the semantic content of the preposition, but rather it is a typical feature of the landmark, which the speaker and the receiver know, which allows an understanding of the spatial relation indicated by means of the PP. Therefore, it is not our aim to demonstrate that there are per se different meanings of $\dot{\varepsilon} \pi$ í depending on the dimensionality of the landmark. Much to the contrary, we believe that the "ideal meaning" of ćrí remains constant in each and every one of its appearances. What happens is that, by seeking the equivalence with a modern language, the translations vary, and we must use different prepositions or periphrases to represent spatial relations that in Greek are expressed by means of غ́ंí. Below we will try to explain the reasons for this anisomorphism. 
In a previous brief paper ${ }^{1}$ we tried to discover what the basic spatial mean-

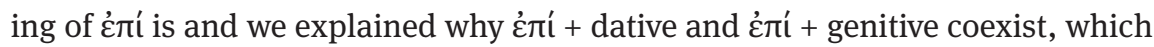
sometimes are synonymous constructions, and other times are not. But there we limited ourselves to the most usual locative meanings, which are those that appear with three-dimensional landmarks (3DL). Here, in the first place, we are going to summarize the conclusions of this work, in order to later try to clarify the uses of $\dot{\varepsilon} \pi$ í with two-dimensional landmarks (2DL) and one-dimensional landmarks (1DL), which are less understood. All of this will allow us to be even more precise with the basic meaning of the preposition.

\subsection{Dative and genitive: first approach to the basic meaning of घ́mí}

As aforementioned, the basic notion expressed by ćmí is the contact of the trajector with the landmark, regardless of the orientation. The examples that are submitted to demonstrate that sometimes there is no contact, are either metaphoric, indicating close proximity, or else they are misunderstood; if '́ní appears it is, precisely, to indicate contact. The starting point is necessarily the construction with the dative, because dative is the typical case of the locative meanings and because all our information in Greek indicates that it is also the oldest construction. ${ }^{2}$

From that point on, the usual practice is to establish two meanings, which Ruijgh (1994) calls respectively SUR (= 'on', 'on top of' with vertical orientation) and PRES (= 'next to', 'at the edge of'). In the manuals one usually reads that in the Ionic-Attic dialect the use of the genitive corresponds to the meaning SUR

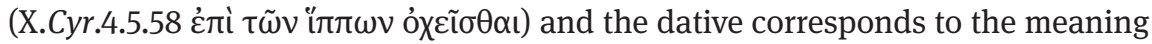

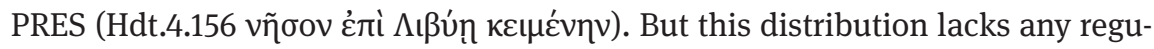
larity, with there being countless examples that contradict it. Especially in Homer,

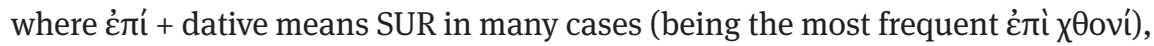
but also in the classical times and later. On the other hand, the construction with the genitive is also used with the meaning PRES, with aquatic landmarks, which

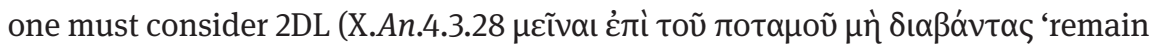

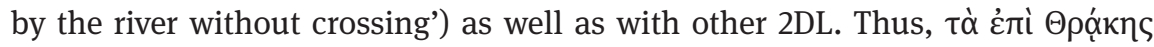
in Thucydides (1.59, etc.), invariably refers to 'the (Greek) cities' or 'areas on the

1 Rodríguez Somolinos (2012).

2 Going farther back, our reconsideration of the basic meaning of ह̇ $\pi$ - fits in perfectly with the data from the Myceanean Greek, where o-pi / e-pi with gen. is not attested. See Morpurgo Davies (1983). 
boundary with Thrace', and the same happens in many other examples misunderstood as SUR when they actually mean PRES.

So, we find a distribution between the dative and genitive use, which is sum-

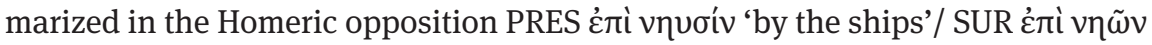

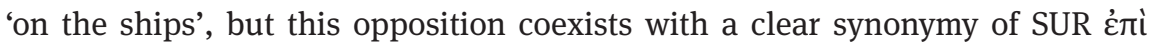

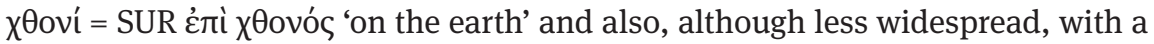

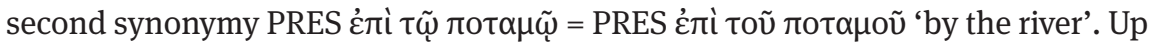
to now all the attempts to explain this situation, as well as the very existence of the locative use of the genitive, have been futile.

The book of Luraghi (2003) reflects well the difficulties in explaining this situation synchronically and diachronically starting from a basic meaning 'on', 'on top of'. Nevertheless, it contains an interesting observation on the opposition ' $\dot{\pi} \mathrm{i}$

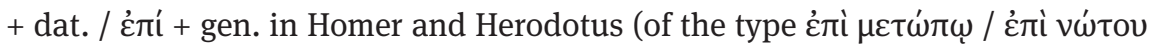
in Hdt.3.28): while Ruijgh sees it as an opposition between lateral and vertical location, Luraghi observes that the genitive indicates a specific orientation, the vertical one, but the dative does not denote it: it only indicates contact. In such a case, the orientation is deduced from common knowledge of the shape of the landmark.

Several years earlier, Ruijgh (1994) had tried to explain both meanings SUR and PRES of $\dot{\varepsilon} \pi i$ + dative as inheritance from two different constructions, with dative and with instrumental, a situation that he wants to be reflected in the Mycenaean Greek. With the general substitution of the instrumental by the dative,

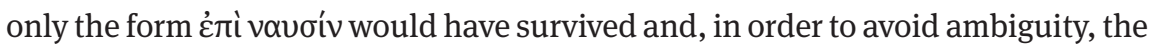

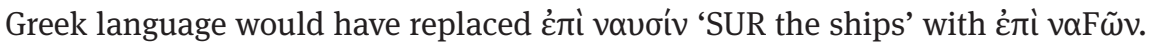
Elsewhere I have criticized this hypothesis as uneconomic, for not taking into account the bulk of the information provided by the Mycenaean Greek, and because it is based on very weak data (Rodríguez Somolinos 2012: 219). But, regardless of the historical explanation, Ruijgh's paper contains two valuable contributions:

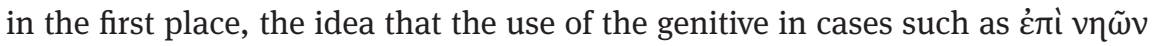
has served to disambiguate meanings. In the second place, the demonstration

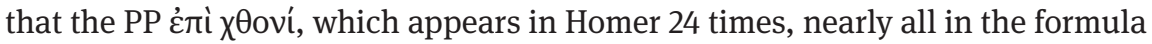

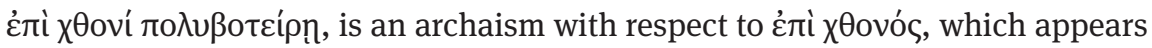
twice in Homer and does not form part of formulas (2012: 145ss.).

By studying in detail the data, we have established a basic locative meaning of $\dot{\varepsilon} \pi \dot{\imath}+$ dative (1), from which in turn two other meanings are derived (2 and 3). And we have explained the appearance of the PP with the genitive as a procedure of semantic disambiguation, which the Greek language turns to at a certain time to specify the superior location, with vertical orientation, while the PP with the dative, the oldest one, only expresses contact. Therefore, we start not from two but rather from three meanings, which are those that we find when dealing 
with 3DL. Along with these 3DL, one must add a special 2DL, which is the earth, the ground. Below we will see why it is special.

\section{Locative meanings of émí with three-dimensional landmarks + the earth}

\subsection{DL meaning 1) غ̇пí 'on the surface of', 'adhered to', 'on'}

This is the meaning that must be viewed as the original meaning of ćmí, expressing contact, regardless of the direction. When a trajector is in contact with a 3DL, it is actually in contact with the most external part of it, that is, with the surface. We can establish, then, a basic meaning 'in close contact with the surface of' the landmark, which we abbreviate as 1 'on', 'adhered to' (Figure 1).

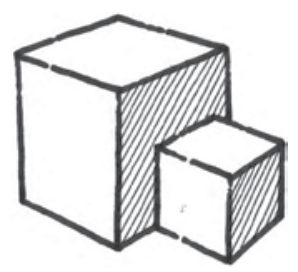

Fig. 1: 3DL meaning 1

There are different circumstances that impose or allow other translations:

a) It is very common that the trajector has in turn a broader surface. That is to say, the area of contact between the trajector and the landmark is large. The trajector, then, is (superposed to, covering) the landmark: Il.9.490

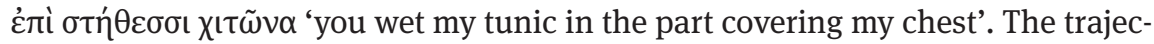

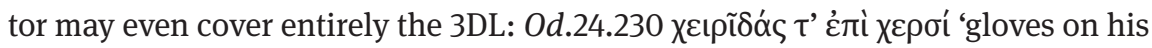

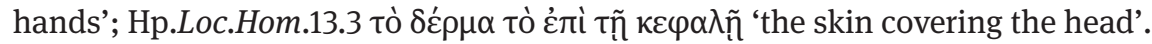

It may be interesting to recall here the etymological relationship between Greek ćrí (Mycenaean Greek e-pi, o-pi) and Latin ob, which is usually accepted but has always had to face serious semantic difficulties. The generalized idea that Gr. '̇ंí (as in ai. ápi, pi-) basically means ‘on', ‘on top of', with vertical orientation, does not match with the traditional explanations of Latin $o b$ as 'in front of', with the progressive precisions 'in an opposite position to' and 'face to face'. However, both forms can be much closer approximated if, as has been recently 
proposed by Van Laer $(1998,2010)$ the original meaning of Latin $o b$ - is that of 'recouvrement'. ${ }^{3}$

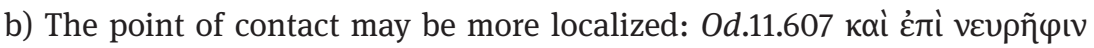

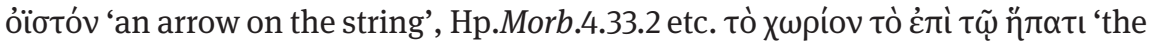
place adhered to the liver', which is the name of the gallbladder, actually located under the liver.

c) The contact is managed or is maintained by means of pressure or support

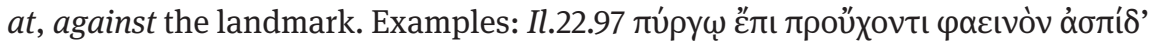

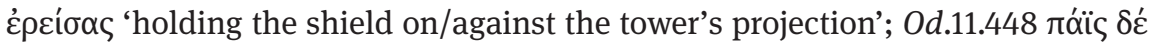

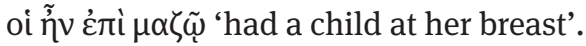

d) The contact is often produced as a result of an action (tying, adjusting,

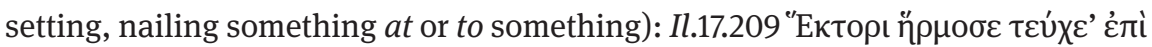

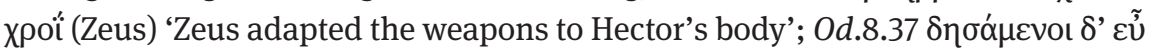

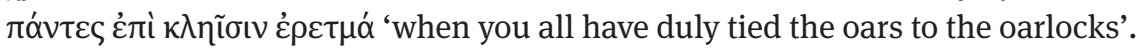

e) The contact may be at a time point, as a result from an impulse against

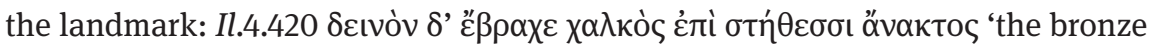
resounded terribly against the king's chest'.

f) We can understand as a figurated use of this meaning when the landmark actually forms part of the surface but it is seen as something added to the land-

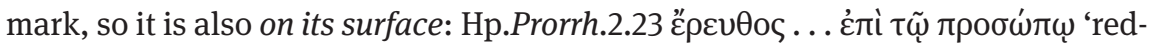

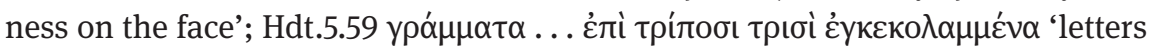
engraved on three tripods'.

\subsection{DL meaning 2) ع̇mí 'on', 'on top of'}

This meaning is nothing more than meaning 1 when the location of the trajector with respect to the landmark is in a relation of verticality, that is, when there is an upper location, such as that of a book on a table (Figure 2). We can find static situations or situations that imply any type of movement that ends on the landmark. In many of the examples of meanings 1 and 2 we may translate $\varepsilon \pi i ́$ in English as 'on', in Spanish sobre, French sur, German auf, Italian su, etc., but one should always bear in mind that these prepositions may indicate superior location as well as contact with the surface, regardless of the orientation. So, in the poster that we put on the wall we have meaning 1, but when we put a book on the table we have meaning 2 .

3 Van Laer (1998 and 2010: 79ss.), including the previous bibliography. For an excellent exposition of the related forms in the different languages, see Berenguer (2000: 319ss.); on the italic forms, Berenguer (2000: 325s.). 


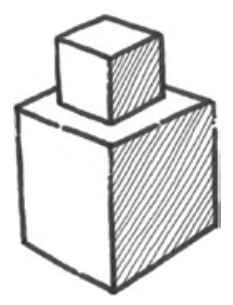

Fig. 2: 3DL meaning 2

From a given moment, the genitive is used, a case that was available, since Érí never had ablative uses, in order to specify the superior location, with vertical orientation. ${ }^{4}$ The substitution of one case for another is clearly in development in Homer, with around 180 examples of $\dot{\varepsilon} \pi \dot{\imath}+$ gen. in local uses compared to more than 700 of $\dot{\varepsilon} \pi \dot{\imath}+$ dat. But in addition, the construction with the genitive will also assume other meanings originally typical of the dative. First of all it will take on

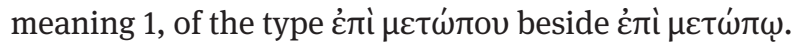

\subsection{DL meaning 3) ह̇ini 'very close to', 'next to', 'by'}

This meaning, which is found especially with the dative case, cannot be understood as an evolution from meaning 2, but is easily explained as a metaphoric use of the notion of contact, as Luraghi ${ }^{5}$ explains, that is, from meaning 1 . This third meaning appears when the landmark is no longer the human body or small objects, but rather three-dimensional elements of greater size, such as ships,

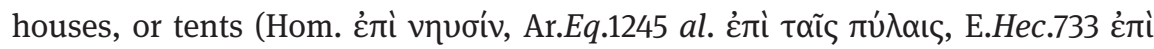
oknvoĩs), and the orientation is lateral (Figure 3). In turn, the trajector has also changed; in the most cases it consists in human beings settled on the ground. If,

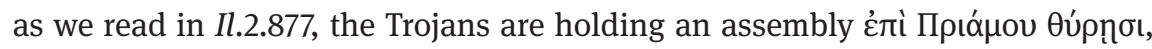

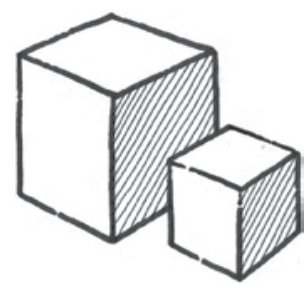

Fig. 3: 3DL meaning 3

4 See Rodríguez Somolinos (2012).

5 "Occurrences where epi with the dative does not imply contact still denote close proximity, and can be understood as based on a metaphor, according to which proximity is equated to physical contact” (Laraghi 2003: 313). 
our knowledge of the characteristics of the trajector "men" and of the landmark

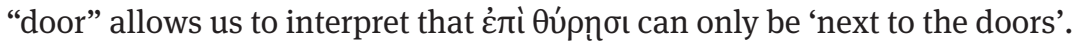

Although with 3DL such as ships or tents the meaning "next to" is especially clear, actually it is much more frequent with 2DL. We will return to this below.

It is important to insist that '́ंí still indicates a very close proximity; $\dot{\varepsilon} \pi \dot{\imath}$ $\pi о \tau \alpha \mu \tilde{\omega}$ is 'on the very bank of the river', 'at the edge of the river'. In the same

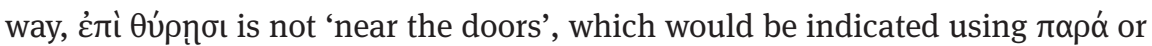
прó,, but rather 'at the doors', Sp. a las puertas (Lat. ad portam, ad portas). Here the equivalence appears with $a d$, the Latin preposition semantically closest to $\varepsilon \pi i$ where there is no vertical orientation, both in the locative and lative uses.

\subsection{Reasons for the disambiguation and preservation of غ̇ií + dat. with meaning 2}

In our opinion, the construction with the genitive arose to disambiguate the spatial relations represented in 1 and 2 . That is, $\dot{\varepsilon} \pi \dot{\imath}+$ genitive is a marked term that specifies vertical orientation, in opposition to غ́лí + dative, which represents any location with contact. Why is the need felt to specify that there is a vertical orientation? The answer is easy: because there are landmarks that have more than one surface, that is 3DL, where there may be and in fact there is ambiguity, since the trajector may be "on top of" it (2), or "adhered to" one of its sides (1) or "close to" it (3). The most representative case is that of the ships, because it is the one that in

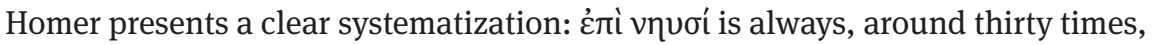

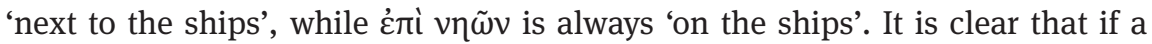

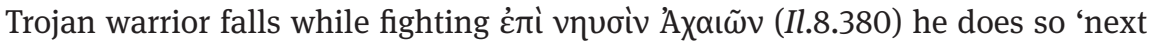

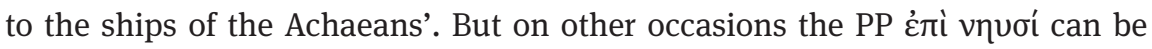
ambiguous, and in fact continues being so, as we can verify by reading modern translations that often mistakenly interpret it.

Nonetheless, the fact is that, independently of the development and expansion of ćri + genitive, we find many cases in which the construction with the dative continues indicating superior location. As Ruijgh saw and our explanation

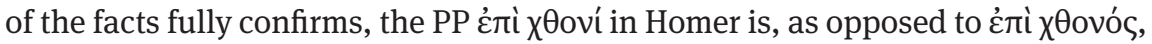
an archaism. But if we take into account certain circumstances we will see that the question is more complex than it appears, and that the label of "archaism" or "poetic archaism" is insufficient to explain all the cases.

In Homer and the later poetry of epic influence there are, in effect, many cases. But the fact is that '̇ं $\mathbf{i}$ + dative continues being used to indicate the upper location ('on', 'on top of') throughout the entire history of the Greek language, parallel to the progressive extension of $\dot{\varepsilon} \pi \dot{\imath}+$ genitive, and coexisting with the 
meaning of '́rí + dat. supposedly typical of the Ionic-Attic and the koiné, which is meaning 3 'next to'. On one side it appears not only in epic poetry but also in lyric, tragedy, comedy, as well as in Hellenistic and imperial poetry: S.Ant.134 غ̇ंi yã

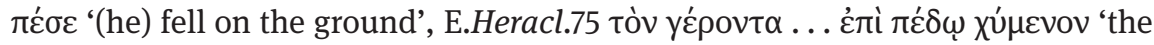

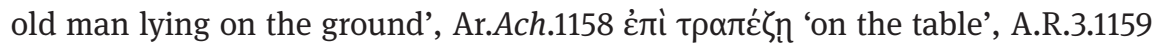

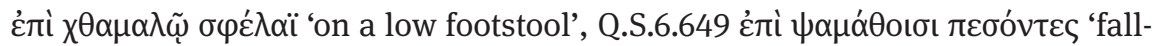
ing down upon the sands', etc. However, it also appears here and there in practically all the Ionic and Attic prose, as well as in the later prose: Hdt.5.12 öyyos

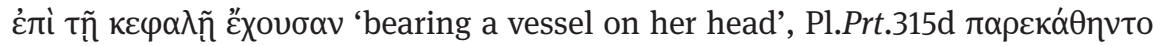

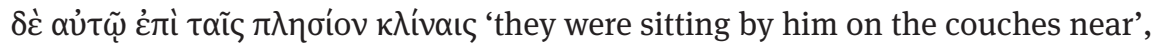

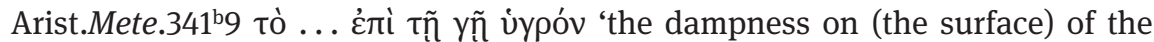

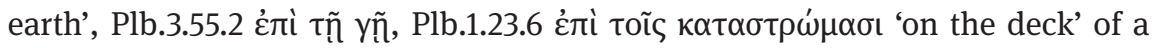

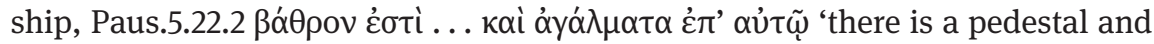
statues on it', etc.

If we ask ourselves why both constructions, one old and another new, coexist with the same meaning 2, when the new one has come to replace the older one in order to avoid ambiguities, we can only answer that the older one continues being used only where there is no ambiguity. We can verify this by classifying the types of landmarks that appear in PP with the dative with meaning 2:

a) The earth's surface. The most frequent case in which ' $\pi^{\prime} i$ + dative presents meaning 2 'on', 'on top of' is undoubtedly where the landmark is one of the names of the earth. Our next question will logically be: why is there no ambiguity in the

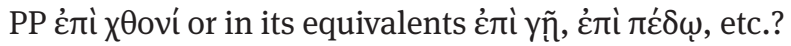

The reason lies in the fact that the landmark "the earth" (which from the human point of view is two dimensional, that is, constitutes a surface) has the exceptional property, in comparison to other 2DL, of being unlimited, that is, it lacks ends or limits. Or, if it has them, they are too far distant from the most frequent spatial situations described in the PP. That is to say, the landmark constitutes in itself a surface and only a surface. If a warrior falls wounded to the ground, there is no other location possible for this human trajector than the upper surface, which is the only one, of the earth. Since there is no ambiguity, in this case

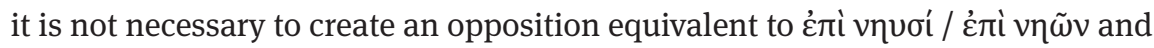
it can be still used.

It is important to emphasize that we are not dealing with a meaning other

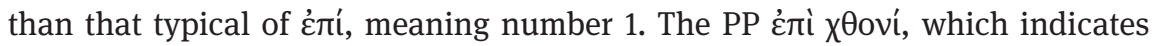
close contact, assumes in this case an added relation of verticality that is obligatory given the physical features of the landmark, and which is unequivocal because the speaker knows these features. The fact that the trajector is on, on top of the landmark is, in this case, an inevitable consequence of being in contact with it. The same occurs with any other example referring to the earth: in Il.23.876 غ̇ì 


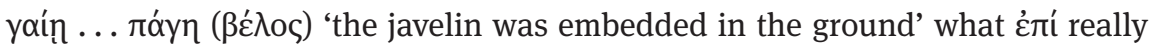
indicates is the close contact, resulting from an action, between the javelin and the earth; the vertical orientation is circumstantial. But it further indicates that it is embedded in the surface, compared to the spear which goes deeper: Il.10.374

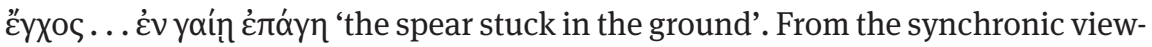
point we find cases such as these, above all, in Homer and Herodotus, and we interpret them as synonyms of '̇ं í + gen. meaning 'on, on top of'. However, at least in their origin, they are not synonyms.

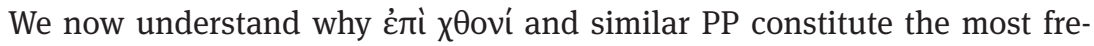
quent case in which $\dot{\varepsilon} \pi \dot{i}$ + dative has meaning 2. But we have seen that this is actually an exceptional case. What happens with the 3DL, where there may be more than one surface or more than one side on which to locate the landmark? Is there no ambiguity in them either? Why?

Reviewing the above examples and adding some others, it is possible to see how it deals in general with landmarks that contain a horizontal surface and possibly others, but usually without introducing ambiguity, either due to the shape of the landmark, which is known, or due to the linguistic or extralinguistic context of the PP. We may organize them in three groups:

b) Parts of the human body "on" or "in" which things may be supported or carried in a relation of verticality: the head, shoulders, and knees:

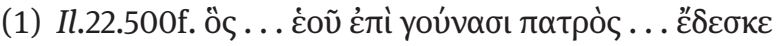

'who used to eat upon his father's knees'

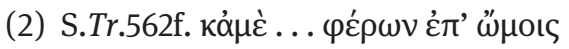
'also carrying me on his shoulders (Nesus to Deyanira)'

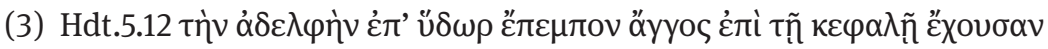
'they sent his sister in search of water, with a vessel on her head'

c) Names of seats. This is, statistically, the most frequent case after the ones

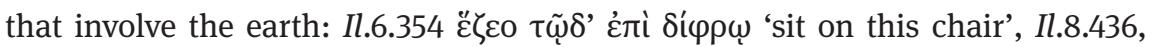

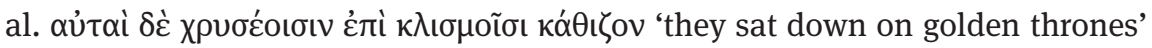

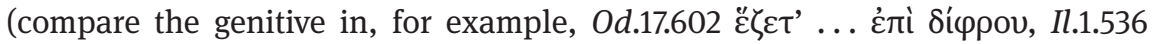

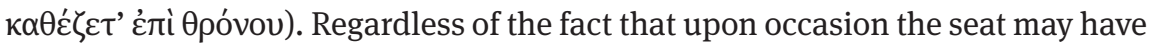
more than one surface, as a human trajector always appears and the verb always means 'to sit', 'to be seated', or 'to get somebody to sit', there is no possible ambiguity. When one wants to specify that the trajector is by the seat, another

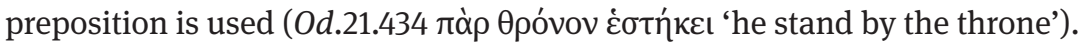

d) Names of other objects that constitute horizontal surfaces whose specific function is to sustain or carry things, or to serve as a base for other things: bases 
and pedestals, tables and trays. Here again there is no confusion, because the knowledge of the form and function of the landmark, with the help of context,

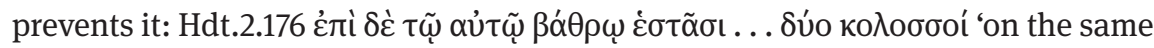
pedestal there are two colossi'. When Aristophanes and other comic poets speak

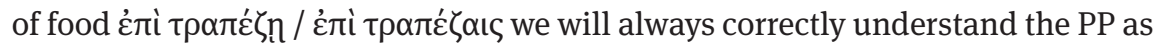
'on the table' (Ar.Ach.1158, Telecl.1.7, etc.). This explains why still in the Gospel

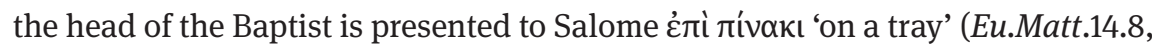
11, Eu.Marc.6.25, 28).

But, in spite of everything, with certain landmarks that have more than one surface or more than one side, the two meanings are still possible, sometimes the two are documented in contemporary texts and, depending on the context and the type of trajector, may lead to ambiguity. Identified ambivalences are, for

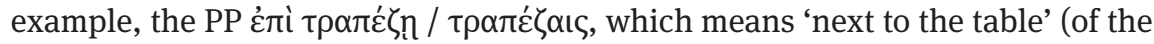
money-changers) in Pl.Hip.Mi.368b and the Attic orators. The meaning arises from the general context and from the type of trajector, which now is human. In a similar way, غ̇ंi $\pi u \rho i$ will be 'on the fire', 'in the fire' when speaking of fish that

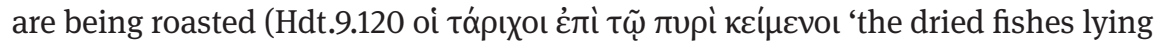
on the fire') but it will be 'next to the fire' when speaking of the soldiers that stand

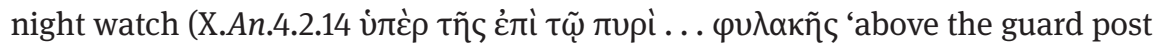
... by the fire').

The clearest example of ambivalence and ambiguity concerns the altars. Nor-

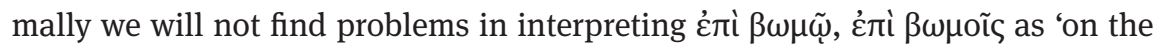
altar', 'in the altar' when the trajector consists of victims: Hdt.4.35 $\tau \tilde{\omega} \nu \mu \eta \rho i ́ \omega v$

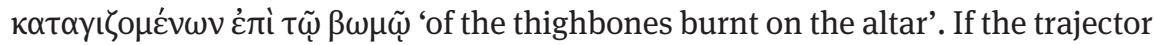
is human the meaning of the PP will change, and necessarily will mean 'next

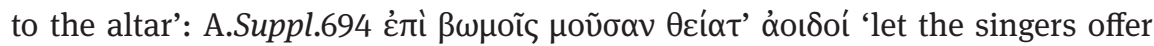
their muse (that is, let them sing) next to the altars'. The issue may become complicated, if the victims, still alive, are 'next to the altar': Plb.16.25.7 غ̇лi $\delta \dot{\varepsilon} \pi \tilde{\alpha} \sigma$

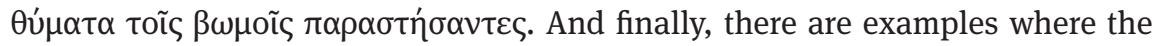

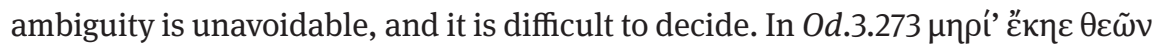

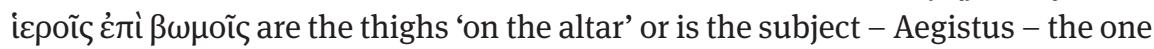
who burns the thighs 'next to the altar'?

Some PP are unanimously understood as 'on top of', but they are much more likely to indicate proximity. An Attic author such as Xenophon, if he uses

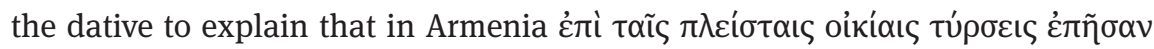
(An.4.4.3) it is because he wants to emphasize that in that land the majority of the houses had towers attached, "adhered" to the houses, not on top of them, as all the translators interpret it. In general, and regardless of the fact that there are ambiguous cases, it is usual to ignore meaning 3), which leads to many wrong interpretations in translations, commentaries, and bibliography in general. 


\section{5 Ėmí + dative in other types of landmark}

Along with the four types $(\mathrm{a}-\mathrm{d})$ of landmarks that we have seen (3DL + the earth), there are three other groups of examples of ' $\varepsilon \pi$ ' + dative in which the PP is always interpreted according to meaning 2 'on', 'on top of', with vertical direction. The three constitute, actually, the most frequent types and the most persistent landmarks with which this meaning appears, and in none of them does there seem to be, in principle, any possible ambiguity:

e) In the first group the landmark is a place name, which normally is on the earth or on any type of ground, for example, of a building. Some examples:

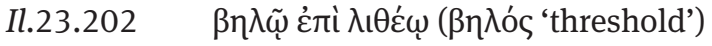

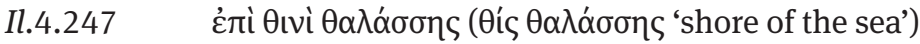

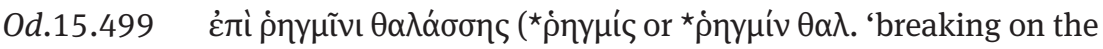
beach, surf'

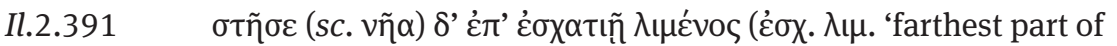
the harbour')

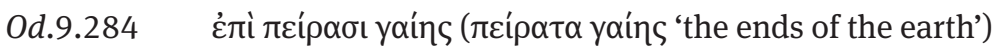

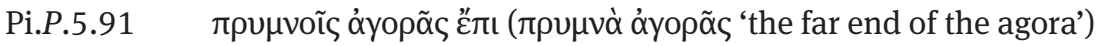

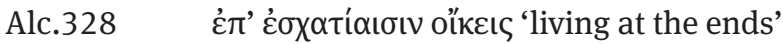

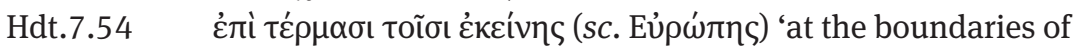
Europe'

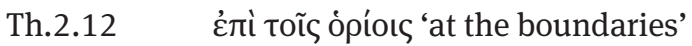

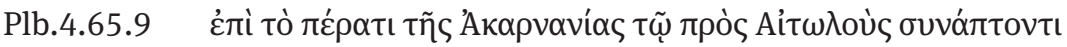
'on the border of Acarnania lying next to the Aetolians'

f) In the second group, the landmarks usually are capes or promontories that project out into the sea, often with its name:

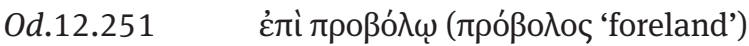

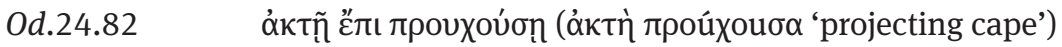

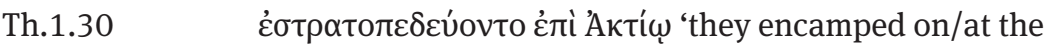
(promontory) of Actium'

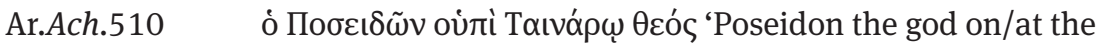
(cape) Taenaron’

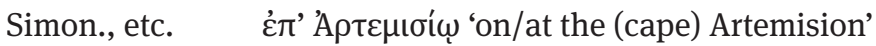

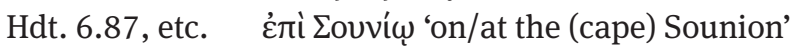

g) In the third group we bring together all those landmarks that constitute elevated elements settled on the ground, such as mountains or trees: 
Il.5.522s.

Hdt.2.12, etc.

Sapph.44Aa.6

Paus.1.42.4

Il.4.484

Arist.HA 559a13

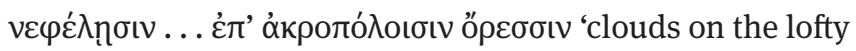
mountains'

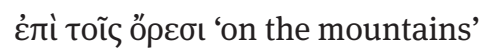

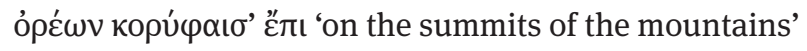

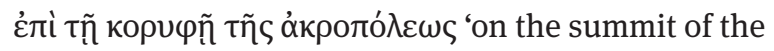
acropolis'

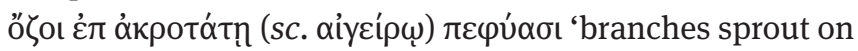
the highest part (of the poplar)'

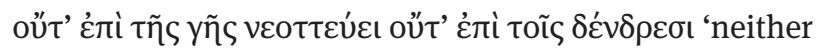
does it build its nest on the ground nor on the trees'

It is surprising that no attention has ever been paid to the fact that '̇ंí is the preposition systematically used when speaking of capes, when speaking of mountaintops or treetops, and with the place names that we have gathered in group e). Either with the dative or the genitive, the use of ' $x \pi^{\prime}$ in these cases is nearly constant and very persistent, as we have said, since we continue to find it abundantly used in all times.

In order to explain the reason, we should be aware of a common circumstance to all the landmarks of groups e), f), and g), which have never been related to each other until now, and this circumstance is that they all refer to ends. So, in group e) we have different names that refer to the end or edge of a limited 2D space. In group f) we have the location at the end of projections of land that enter the sea. In group g) the PP indicates a location on top of an elevated element in a vertical position, perpendicular to the horizontal axis of the earth.

In the traditional interpretation of these landmarks only the vertical orientation has been taken into account, and for this reason it has been thought that they

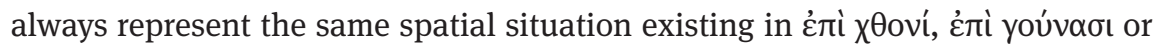

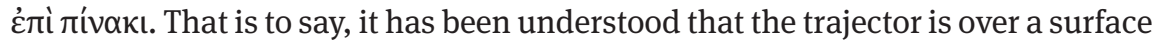
or a point on a surface. The only appreciable difference is that in groups e) and f) the translation 'on' is not always suitable for place names, especially im the case of proper names, as happens with capes. For this reason, other translations are usually chosen: 'in' and 'at' (Fr. en, à, Sp. en, etc.).

Actually, in order to interpret correctly these three groups of PP, it is essential to dispense with the orientation and pay attention to the dimensionality of the landmarks, but not necessarily as we see them, but rather as they are conceptualized. With the landmarks of group e) - a beach, a territory, a room - it is clear that they are 2D spaces, and the trajector is located on some point of them. But we are not dealing here with unlimited surfaces such as the earth; we now face limited two-dimensional spaces, such as a piece of land or a fabric, and as they 
are limited there are more possible locations for the trajector other than the upper surface; there are the borders, ends or limits.

Less evident is the dimensionality of groups $\mathrm{f}$ ) and $\mathrm{g}$ ). However, if we leave the orientation apart, as we have seen it is a secondary element, we will observe that they are conceived as an identical type of landmark: something lengthened at whose end the trajector is located. The location is no longer on a surface, but rather at an end as in the previous group. But this is not the end of a 2D space, but the end of an element conceived as 1D, like a line, that is, its end, extremity, top, point, etc. (Sp. punta or cabo < Lat. caput). For this reason we will study each group of examples within the sections corresponding to 2DL and 1DL, comparing them with other unequivocal examples in which the orientation cannot interfere.

\section{Locative meanings of દ̇ní with limited two-dimensional landmarks}

The study of countless examples has allowed us to conclude that when ćrí is joined to a limited 2DL in the dative it never indicates a location 'on', 'on top of' the surface delimited by its borders, but a location 'in contact with', 'close to' these borders. This implies that one must consider misunderstood the examples of PP with 2DL interpreted with vertical orientation. For example, in the entry ¿́rí of LSJ, within the section "B with Dative, I of Places upon just like the gen."

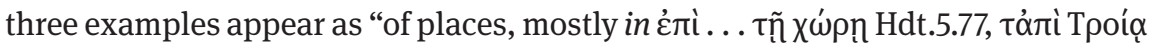

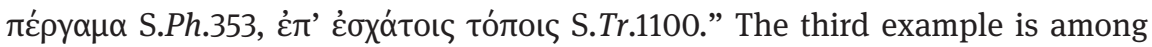
those that we have just seen, with names of ends, and of the second we will speak below. As for the first, the study of the use of $\dot{\varepsilon} \pi \dot{i}+$ dat. in Herodotus and the existence of very close parallels have led us to consider it an abstract, not spatial, usage. $^{6}$

\subsection{DL meaning 1) ह̇in 'in contact with the end of', 'next to the edge of'}

We can see this meaning, in principle, as the necessary adaptation for limited 2DL of the basic meaning of '̇ंi that we have established above. It is clear that the

6 DGE s.u. érí B III 7 a) indicating control, surveillance or command, in charge of, at the forefront of, in command of. The parallels are, especially, ICr.4.72IV.35 (V A.D.) and D.H.2.16.1. 
translation will normally be 'in' in the case of terrestrial landmarks and 'at the edge of', or 'next to' in the case of aquatic landmarks.

It is possible that, precisely in order to avoid ambiguities, there are virtually no PP where ć $\pi$ í is directly joined to a non-aquatic 2DL in the dative, without a noun or adjective that specifies the location in the extremity. The best example is

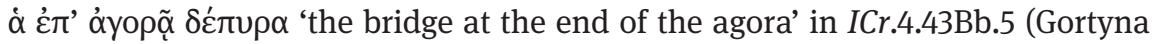
V B.C.). It is usual, as we have already seen in the examples of group e), for the landmarks to be names of ends or limits of a 2D space, which in turn constitute lines of separation between two 2D spaces: thus the coastline is both the end of the land and the border between the land and the sea, the threshold is the line of separation between one room and another, etc. These terms may be of two types:

a) Names of elements that may constitute a limit or border such as Hom.

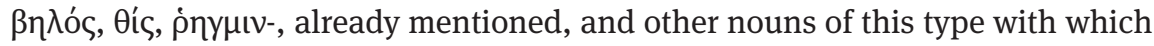

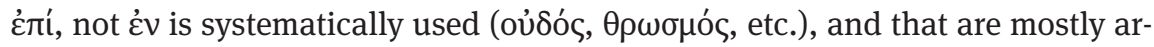
chaic and/or poetic terms. Although in some cases we do not know their etymology, all of them must be interpreted as elements that may serve as a limit or border between two 2D planes. The same happens with the threshold in the phrase $\varepsilon \pi i$

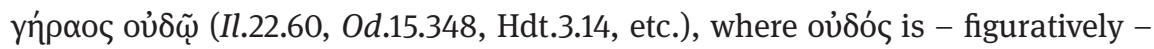
the line that marks the end of old age and the beginning of death, conceived as 2D physical spaces.

b) More frequently they are names with the meaning of 'limit', 'border', or

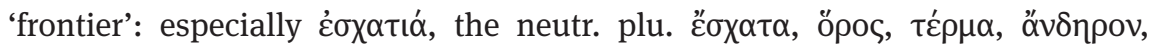

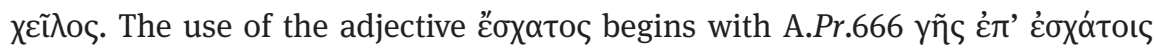
öposৎ 'at the farthest limits of the earth', recharacterizing a landmark that in itself is an extremity.

These and other examples seem to reflect the inherited idea that a person or thing cannot be $\mathcal{\varepsilon} v$ the line that limits a two-dimensional plane or that separates two planes, but that they must necessarily be set on it ('ंזí) but at one side or

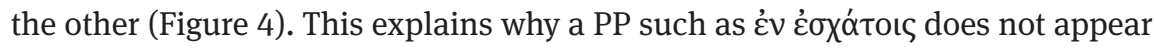
until Euripides, and that this type is always much less frequent than the type ' $\dot{\pi}$ '

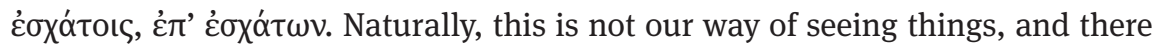
is no reason for our modern languages to be forced to reproduce this conceptual

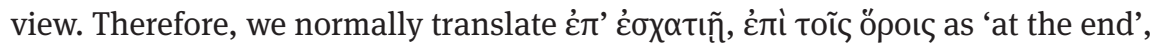
'at the border', غ̇ं' oủ $\delta \tilde{\omega}$ as 'on the threshold', etc.

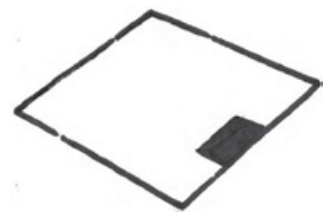

Fig. 4: 2DL meaning 2 
Surprisingly, the use of the genitive with 2DL does have some development without a disambiguating element of this type, although all the examples come

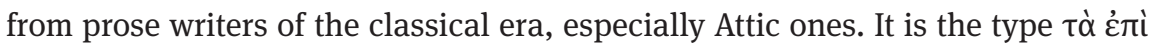

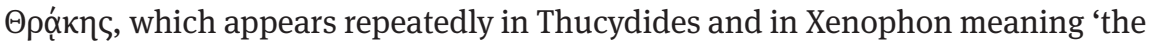
(Greek) areas' or 'cities in contact with the border of Thrace', that is 'the areas or cities bordering Thrace'. It is surprising because, as occurs with the dative, with the genitive this PP can create confusion if the dimensionality is not taken into account, which is the norm. The example mentioned is clear and well-known, but in other cases there is constant confusion in the modern translations: Isoc.12.103

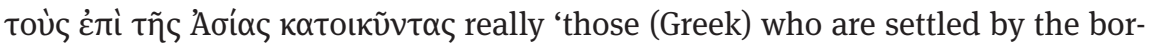

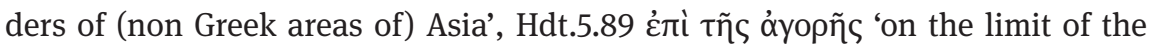
agora', 'by the agora', etc.

Except for these cases, which should be interpreted as an Attic development, it is usual that the same disambiguators appear with the genitive case as we have seen, which indicates that the location is exactly "at the very end of" the landmark. These constructions are much less frequent than with the dative, but are

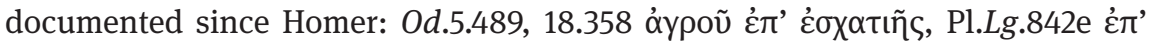

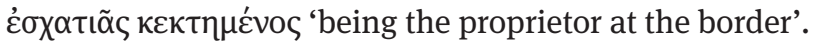

For all of the above, it is easy to understand why the most frequent 2DL with this meaning are aquatic: because normally the context will prevent understanding a location other than the border, and it will not be necessary to use a disam-

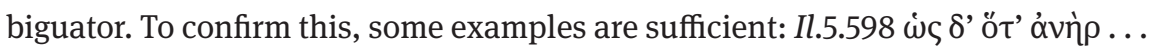

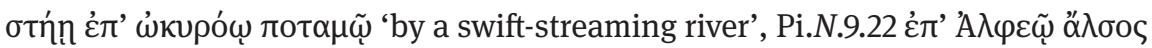

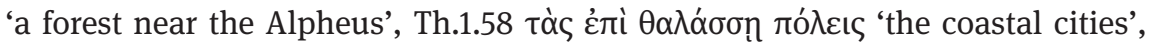

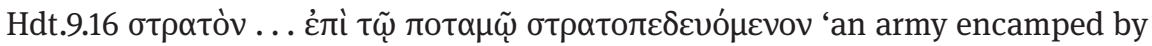
the river'. With the genitive we very seldom find this usage; it appears occasion-

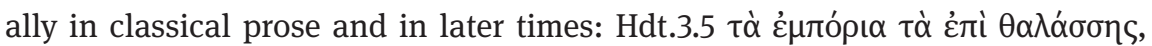

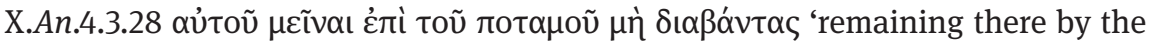

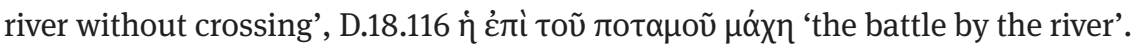

\subsection{DL meaning 2) ع̇mí 'next to'}

The second meaning with 2DL 'next to', 'close to' is really very close to the previous one. In fact, in the majority of the cases that we have seen, the most appropriate translation would also be 'next to', 'close to', because if we want to search for a more exact translation that specifies the contact existing between the trajector and the end of a two-dimensional landmark, we would have to turn to complicated and uneconomic periphrases. 
The reason for distinguishing a second metaphorical meaning is to make room for certain cases in which there is very close proximity but no contact. The proof that this is the result of a metaphorical process starting with meaning 1 , equivalent to what we have established with the 3DL, is in the fact that the contact with the end of the 2DL is no longer as important, but rather the proximity. The cases are usually misunderstood as "in" in the modern translations, a mistake that in this case has greater consequences, because it is not the same to be "in" a city as "next to" it.

We occasionally find this meaning with names of cities, for example in Th.4.14

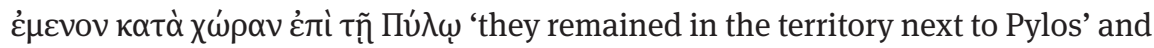

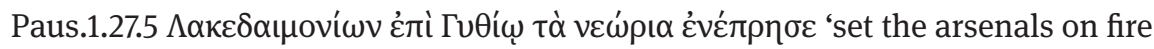
of the Lacademonians next to Gythium'. Another more evident use is with islands

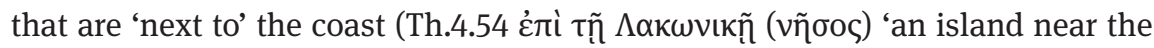

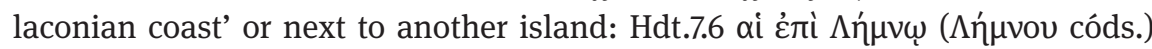

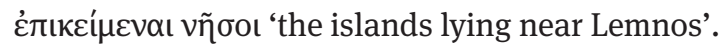

Actually, in these cases the dimensionality with which the two types of landmarks, city or island/coast of the continent are conceptualized, is debatable. I have included them among the 2DL because the landmarks related to the earth or to places are normally considered 2DL, not 3DL. However, it makes no difference in practice, because the location in both cases will be the same and so will the translation.

\section{Locative meanings of żmí with one-dimensional landmarks}

In order to explain the uses and meanings of ' $\pi^{\prime}$ i with 1DL, one must turn to the afore-mentioned phenomenon of "geometric idealization," which consists in the simplification of the dimensions and shapes of actual structures. Since Talmy (1983) it is considered that in all the spatial relations expressed by PP, as well as in the elements that take part in them, conceptual frames are applied that contain relatively basic geometric ideas. In turn, the idealization forms part, along with abstraction and selection, of a more complex process: schematization, “a process that involves the systematic selection of certain aspects of a referent scene to represent the whole, disregarding the remaining aspects" (Talmy 1983: 225; cf. Herskovits 1998).

We believe that the local uses of غ̇ंi reflect a typical process of geometric idealization by which many 3D referents that present a much larger dimension 
than the other two are conceptualized as $1 \mathrm{D} ;^{7}$ that is, a linelike geometric scheme of them is elaborated mentally. This is what happens with objects with a long shape such as a sword, a staff, a belt or a finger; also, as we have advanced, with vertical elements of a larger size such as a tree, a mound, a tower or a mountain, and finally with some special geographic elements like capes for their size and their horizontal direction.

Starting from this premise, as for the 1DL we must distinguish three meanings, which are related in a similar way as are the three meanings with 3DL. The first of them is probably the worst understood up to now.

\subsection{DL meaning 1) غ̇ाí 'in contact with the end of', 'adhered to the point of', 'on the point of'}

As we can see, the meaning is basically the same as in 2DL, but the shape and dimensionality of the landmark have changed, for which reason the end in contact with the trajector is different. It is no longer a line that delimits a surface, that is, an edge, but a point at the end of a 1D element or conceptualized in this way: the point of a spear or of a sword, the end of a cape, etc. (Figure 5). Objects such as these constitute the first group of landmarks that we find, in a type of PP almost exclusive of Homer and Herodotus.

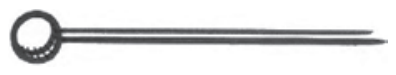

Fig. 5: 1DL meaning 1

There are few examples in which the preposition is joined directly to the landmark, but they are the ones that provide the key to understanding the meaning of '̇ंí with all the types of 1D landmarks. We start with the clearest of them: Herodotus (1.195), describing the attire of the Babylonians, tells us that each one

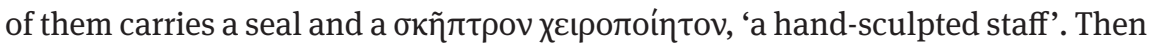

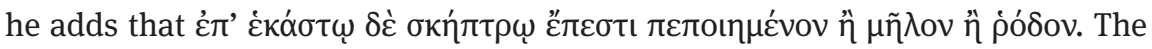
majority of the modern translations reflect the idea that the staff is in a vertical position and above him, a fruit is represented on its upper part ('on', auf, sur, su/in cima a, sobre). Another group of translations opts for indicating a general location in, nel, en the staff. Ruijgh (1994: 135), aware that the apple constitutes the handle of the staff, because the Babylonian staffs are in fact like that, won-

7 See Talmy (1983, 2000: 220), Vandeloise (1991: 5ss., 32ss.), Herskovits (1986: 40ss.). 
ders why what is "above the scepter" is expressed with the dative and not with the genitive. In accordance with his idea that the meaning PRES indicates lateral direction, he explains it by thinking that the use of the dative reflects a horizontal visualization: “'́ní + dat. (all. an) désigne le rapport horizontal entre la pomme fixée à l'extrémité du bâton et le bâton proprement dit.” Paradoxically, Ruijgh gives the exact translation of the PP “fixée à l'extrémité du bâton” within his explanation, but to see it he would have had to dispense with the orientation and have turned to dimensionality.

The solution is reached by understanding that the preposition ćrí joined with a 1D landmark by itself means 'in contact with the end of', 'next to the end of',

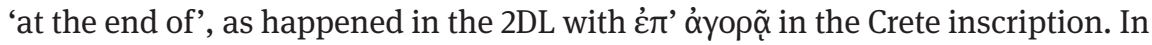
Homer there is a precious example in the passage in which Priam's sons prepare the chariot for their father. After taking out the pieces of the chariot, the assembly of the yoke is described (Il.24.271-273, translation of Murray-Wyatt except words marked in bold):

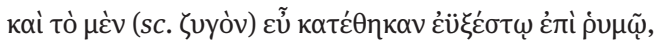

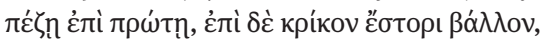

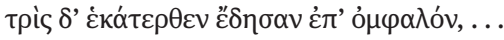

'The yoke they set with care at the end of the polished pole

at its farthest end, and cast the ring on the peg,

and they bound it fast to the knob with three turns to left and right,...'

The majority of translations usually turn to on the pole, sul timone, sobre el timón and equivalents to translate $\varepsilon \pi i$ $\dot{\rho} u \tilde{\omega}$; the French translators usually com-

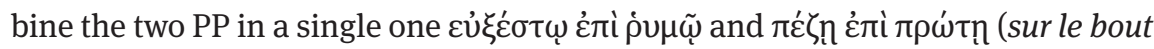
d'avant du timon poli; tout à l'avant du timon poli). In our opinion $\dot{\varepsilon} \pi i ̀ ~ \rho ُ u \mu \tilde{\omega}$ means 'at the end of the pole' regardless of the orientation, as Homer clarifies by adding

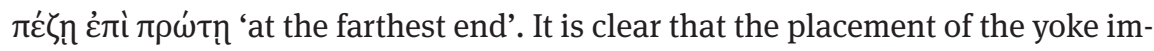
plies some type of vertical movement from above downwards, but this movement is indicated by the preverb of $\kappa \alpha \tau \varepsilon^{\prime} \theta \eta \kappa \varepsilon$, not by the PP.

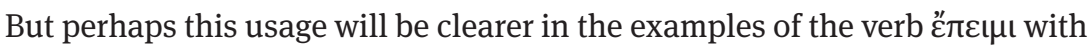
the dative in the sense of 'to be at the end of', that is 'to have at the end'. Thus Herodotus, describing the weapons of the barbarians, provides us with several

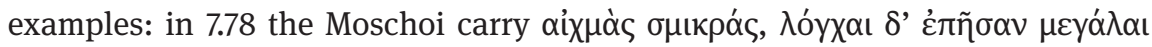
'short spears, but with long points at the end' and in 7.69 we have in the same paragraph two examples referring to the weapons of the Ethiopians: $\kappa \alpha \lambda \alpha \mu$ ívous

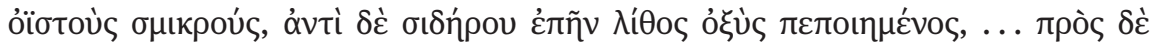

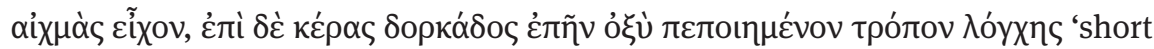
arrows made of cane, but instead of iron on their point there was a sharpened stone ... they also had spears and at the ends they had a gazelle's horn sharp- 
ened like a lance'. ${ }^{8}$ This use is already found in Homer when he speaks of a key

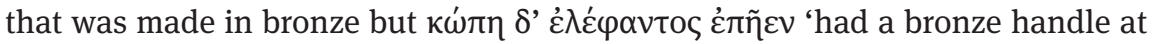
the end' (Od.21.7).

As happened with the 2DL, it is more usual for a disambiguator to appear that serves to specify the location at the end. And the most common disambiguator, almost exclusive, for 1DL is the adjective ökpos, and in particular the PP with the

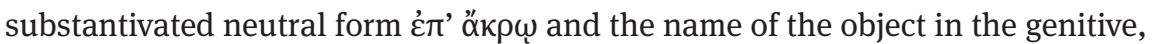
if it is not implicit. Already in Homer there are two examples. In the first one this disambiguator appears with a well-known landmark for us, the pole of the chariot, which helps to confirm our interpretation of that example: Il.5.730 ' $\pi$ '

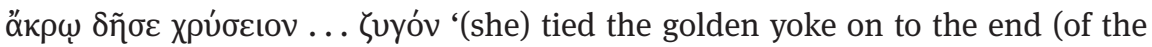

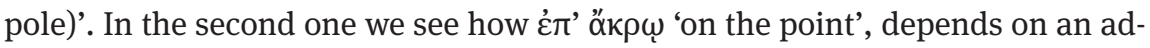

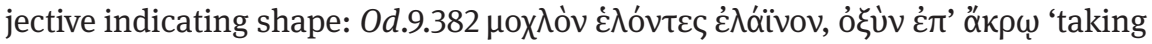

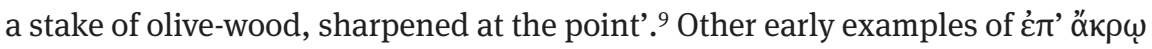

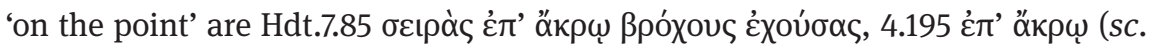

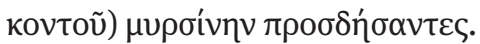

There are isolated attempts to use the genitive in similar cases. This seems the

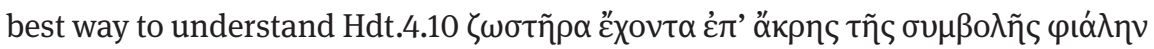
'and a belt with a phiale at the end of its clasp', and the only way to understand

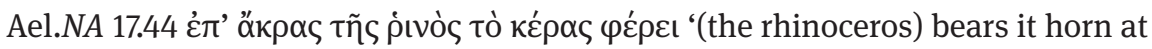

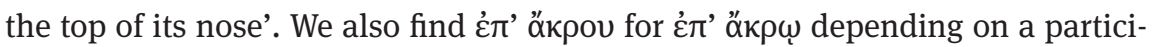

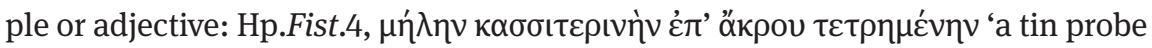

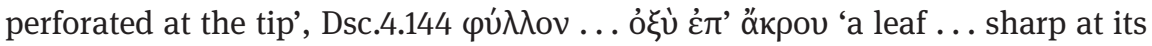
point'.

\subsection{DL meaning 2) ع̇iri 'in contact with the top of', 'at the upper end of', 'on', 'on top of', 'in'}

We have already observed that in different landmarks that constitute vertically elevated elements, such as mountains, trees or towers, the usual preposition for specifying the position of the trajector on their top is $\dot{\varepsilon} \pi$ í and rarely $\dot{\varepsilon} v$, especially in the first centuries of Greek literature. In addition we have observed that in these circumstances the use of $\dot{\varepsilon} \pi \dot{i}$ + dat. persists over a long time, alternating with $\dot{\varepsilon} \pi$ í genitive, increasingly more frequent.

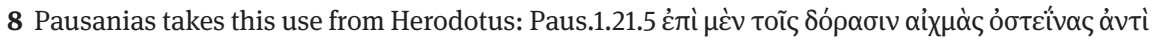

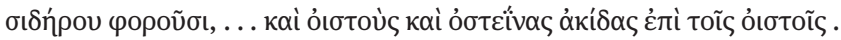

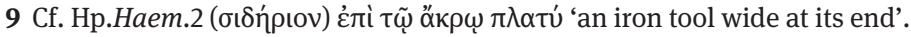


We have also proposed that all this is explained as a result of the same geometric idealization of these landmarks that are raised from the ground as 1D bodies. By being conceptualized in this way, the preposition '̇ $\pi$ í is used for any trajector which is at its peak. As occurred with the 3DL, the verticality of the landmark with respect to the earth imposes a vertical orientation in the spatial relation that is established between them. And, as in the previous case, the exact original meaning of the preposition is 'at the end of', in this case 'at the (upper) end of' (Figure 6). But we do not share this conceptual view; for us, elements such as a mountain or a tower are not one-dimensional. The translation may already be simply 'on', 'on top of' or 'in', as with the 3DL, and for this reason these cases have usually been assimilated to them.

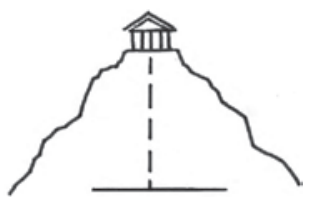

Fig. 6: 1DL meaning 2

In this case there may not be a disambiguator, because it is not necessary:

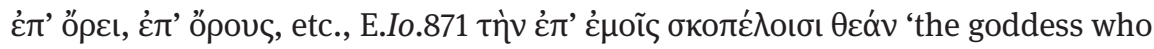
lives on the peak of my rock', etc. Trees are another usual landmark: Theoc.5.47

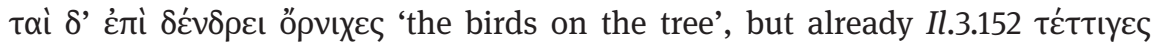

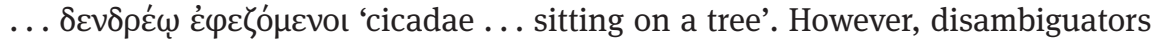
also appear when trying to specify that the peak is being referred to: Il.5.523

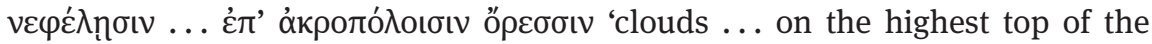

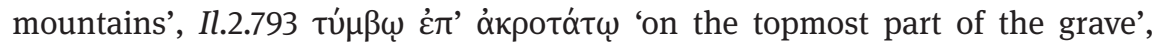

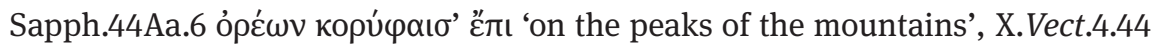

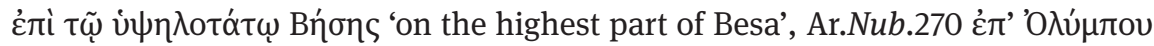

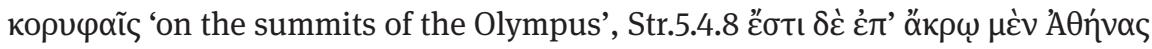
icpòv 'there is a temple of Athena on the top' (that is, the Parthenon), Paus.1.42.4

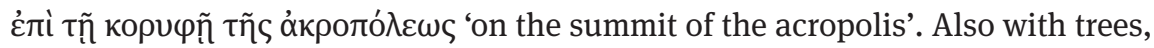

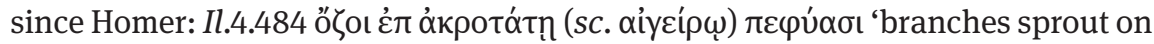
the highest part (of the poplar)'.

This explains, finally, the use of $\dot{\varepsilon} \pi$ i with other landmarks where the onedimensional conceptualization is more difficult for us to see, especially concerning cities. But it deals with elevated cities, acropoles, as the context indicates.

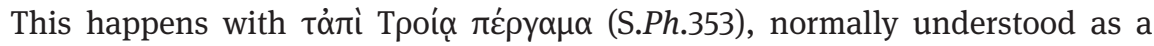
special case of '̇ंí + dat. 'on', with the name of a city, translatable as 'in', which would be completely exceptional. Actually, દ̇ंì Tpoía must be seen as 1DL, in- 
dicating 'at the highest part of Troy', 'at the top of Troy' which we know is an

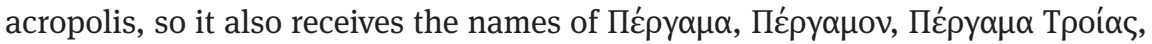

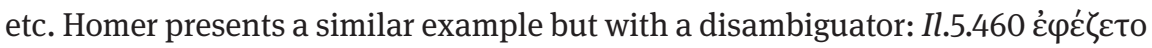

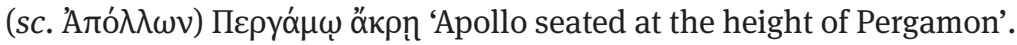

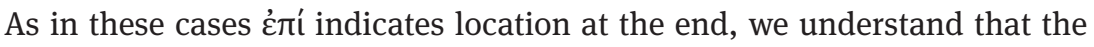
preposition $\dot{\varepsilon} v$ does sometimes appear with a landmark such as the mountains. There may be this geometric conceptualization as a 1D element, but there may be others, since a mountain may have more places where a landmark can be located.

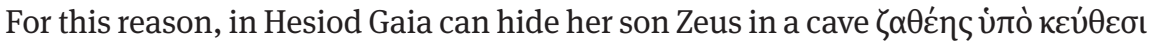

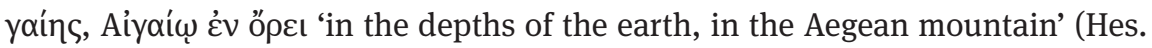
Th.481), or the exiles that took refuge in the mountain may be oi $\varepsilon v \tau \tilde{\omega}$ ôpع

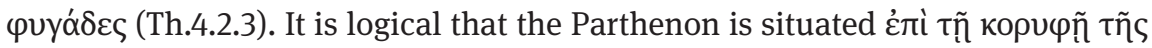

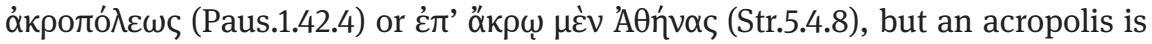
also a city, which constitutes a large space where any type of general or particular

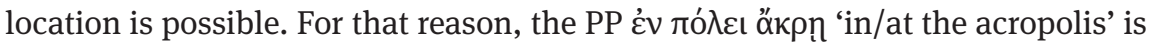

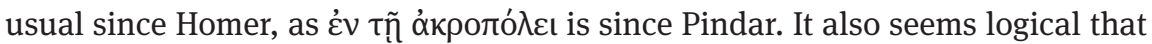
¿่V appears when the landmark is plural, indicating a broader localization. For

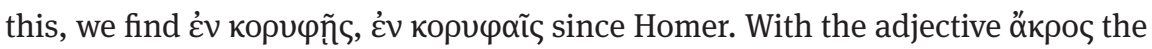

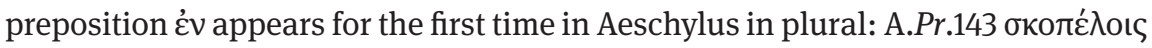

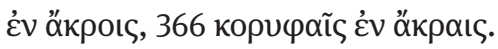

\subsection{DL meaning 3) ع́rí + dative 'at the end of' a cape or headland}

We distinguish this meaning from number 1 for this specific type of geographic landmark because we cannot consider that there is the same relation between a wooden arrow and the metal point that is attached to it, on the one hand, and between a cape and the temple or the city that is at its edge, on the other hand.

Almost without exception, when one speaks in Greek of something located on a cape, a headland, or any projection of the coast, the preposition ć $\pi$ í is used with the dative. And, by metaphoric extension, for any trajector located "next to" or "very close to" a cape, normally in the sea - an anchored fleet, a naval battle -, ¿́rí is also used. It can only be explained by the same process of geometric idealization that we have seen, according to which a portion of land that projects from the coast and enters the sea is interpreted as a 1D element. And in order to express the location of a trajector that is at its edge, only غ่ $\pi$ í with the dative case can be used.

As we have said, there are practically no exceptions in this case, which

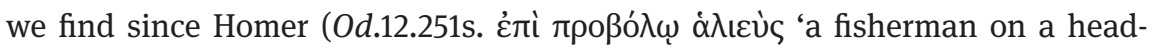




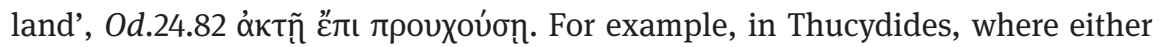
of the other two meanings of ' $\dot{\pi} i$ ' + dative with 1DL is lacking, this other meaning appears, probably because the type of landmark prevents any ambiguity:

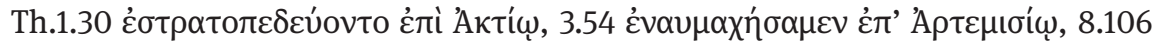

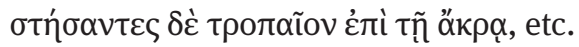

\section{Conclusions}

\subsection{What does દ̇mí really mean? Dimensions and limits}

From all that we have seen, the conclusion is reached that in the locative uses of the preposition '̇ंí there are remnants of a system in which only غ̇лí + dative exists to express contact of the trajector with the landmark, in opposition to other prepositions that express different locations without contact or with different degrees of proximity to the landmark. In this system, the specific meaning of é $\pi^{\prime}+$ dative, that is, the exact localization of the trajector, is deduced (i) from the knowledge of this basic semantic notion of ' $\pi^{\prime}$ i and (ii) from the knowledge of the shape and dimensionality of the landmark. The basic locative, not metaphoric, uses of $\dot{\varepsilon} \pi \dot{\imath}$ + dative must be understood according to the following table:

\begin{tabular}{|c|c|c|}
\hline Type of Landmark & PP & Meaning \\
\hline 3DL without orientation: & 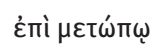 & 'on the surface of the forehead' \\
\hline 3DL vertical: & غ่ாі் $\beta \omega \mu \tilde{\omega}$ & 'on the (upper) surface of the altar' \\
\hline 2DL unlimited: & દ́mì XӨoví & 'on the surface of the earth' \\
\hline 2DL limited: & 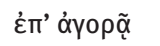 & 'at the edge of the agora' \\
\hline 1DL without orientation: & 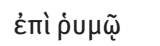 & 'at the end of the pole' \\
\hline 1DL vertical: & 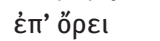 & 'on the mountaintop' \\
\hline
\end{tabular}

As we have been seeing, this system was not perfect, since it provided ambiguities with all the types of landmarks. The use of $\dot{\varepsilon} \pi \dot{l}+$ genitive to specify the

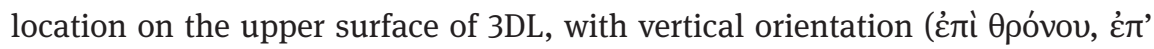
$\dot{\alpha} \pi \eta \dot{v \eta})$, means the beginning of a new system based on orientation, and this new system gradually superposes the first one based on dimensionality. In this

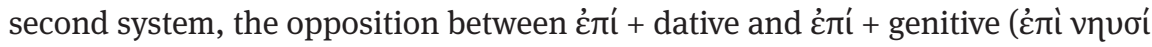
/ Éní $v \eta \tilde{\omega} v$, and similar distribution in Ionic-Attic) carries out an important role. With 2DL and 1DL the first system is practically residual in the classical Greek, since there are very few examples in which the preposition or the preverb is used 


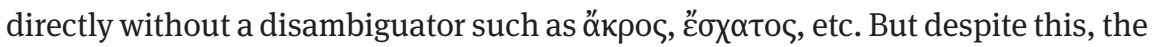
second system never managed to drive out the first one completely. With any type of landmark, with the aid of disambiguators and/or the context, and especially in circumstances where there is no possible confusion, there are traces of the first system here and there throughout the history of the Greek language. And the coexistence of both systems never stops producing superpositions, crossovers, diverse anomalies, and consequently ambiguities.

The difficulties in understanding the locative uses of '̇ंí are due, in the first place, to not having understood the coexistence of both systems. But this, actually, is a consequence of the dissymmetry existing between the conceptual view expressed in this first system - of the referents that take part in the spatial situation and in the same spatial situation - and the conceptual view expressed in the PP with which we try to translate its examples to our languages.

We have already seen how referents that we see as 3D are conceptualized as 1D. We have also observed how in this older system the location at the edge of a 2DL or at the end of a 1D landmark is systematically expressed by $\dot{\varepsilon} \pi$, with the meaning 'in contact with the end of', 'adhered to the end of'. It cannot be expressed by $\mathcal{\varepsilon} v$, doubtless because the most typical meaning of $\varepsilon$, previous to its use to indicate more general localizations, is 'inside of', and it demands a landmark container. But we still have to establish the conceptualization which is perhaps the strangest one to our mental and linguistic structures, as deduced from the table above.

There we can see how identical constructions with ćrí and dative, in one case

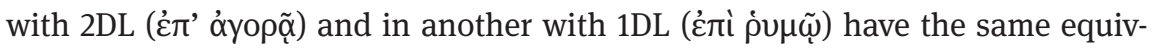
alence for us: 'at the end of' the landmark, because we can assimilate without problems the end of a 2DL and the end of a 1DL, although their shape and dimensionality are different. We visualize the end of a 2DL as a line, and the end of a $1 \mathrm{DL}$ as a point, but we give them the same name. The problem is the dissymmetry in the case of the 3DL, where our translation changes: we do not speak of ends but rather of surfaces. However, what in our language is not equivalent is indeed the same in the Greek language, or at least in the spatial view that this PP reflects.

Our idea is that the difficulties in understanding the spatial relations expressed by means of غ̇ंí result, especially, from not understanding a conceptual view through which the concept of end or limit encompasses ends and limits of 1D bodies and of 2D bodies as well as - and here lies the main difference with European languages - of 3D bodies.

Thus, in modern languages the generic terms serve for the ends of $1 \mathrm{D}$ and $2 \mathrm{D}$ bodies (Sp. extremo, límite, fin, Fr. extrème, limite, Eng. end, limit, Ger. Ende, etc.), regardless of the fact that each language may have specific terms for the end of $1 \mathrm{D}$ bodies (Eng. top, Fr. bout, extrémité, Sp. cabo, punta) or 2D (Eng. edge, Fr. bord, 
côté, Sp. borde, orilla, margen, canto, etc.). However, the generic terms never designate surfaces, because they are not conceptualized as ends.

The opposite view is reflected in the PP with غ̇ंí regarding 'the farthest end' of something, a view whose original chronological stage we do not know, but which the Greeks inherited in their linguistic structures, without necessarily being always aware of it. All this makes us turn our eyes again towards the "ideal"

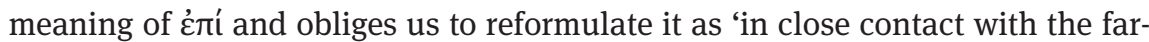
thest end of' or maybe more exactly 'in close contact with the most external part of', which can make its use with 3DL more understandable. With the 2DL there is no problem in understanding that their limits are the most external part, as with the 1DL. As this conceptual view does not coincide with ours, we need to perform different adaptations to our linguistic structures to represent the meaning of ć一i with the different types of landmarks, since we do not have a single equivalent for all of them.

It seems logical to think that this conceptualization does not appear only in the PP with غ̇ $\pi$ í, and one may wonder if there are other traces of it in the Greek language. Indeed, we can find some amount of evidence that points to it, but the main reflection of this conceptual view is doubtless in the adjective ökpos which, as we have seen, plays an important role in the PP with ćit. Only by turning to this conceptual view can we understand why the adjective ökpoৎ means 'that is at the end or point', its most common meaning, with any orientation, as well as 'that is on the surface', which is surprising for Chantraine (1968:

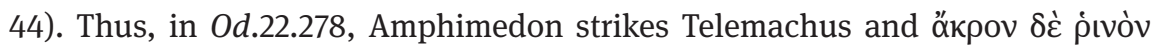

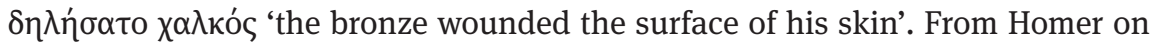

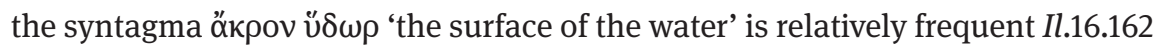

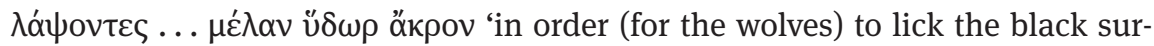

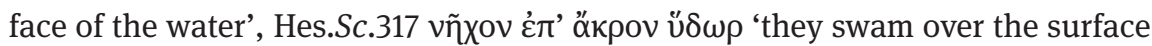

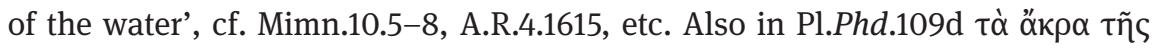

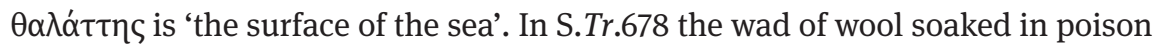

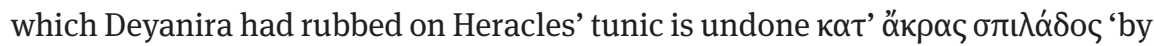
the surface of the pavement'. ${ }^{10}$

However, what may interest us more is that we also find this adjective or its

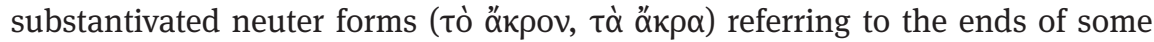
two-dimensional referents. Although this is less frequent, there are clear ex-

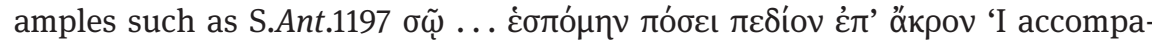

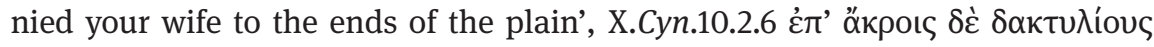

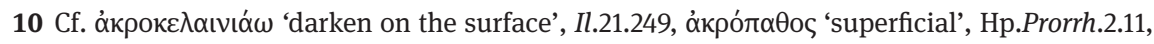
etc. 


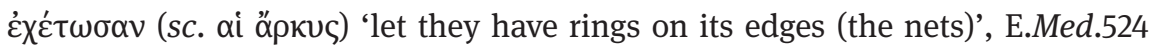

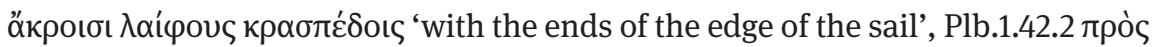

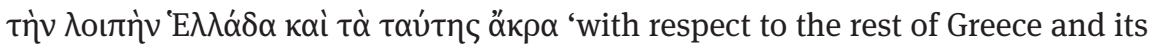

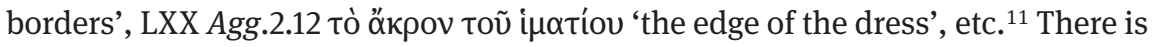

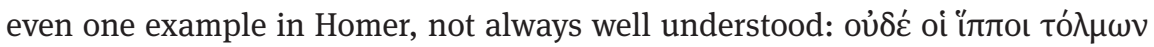

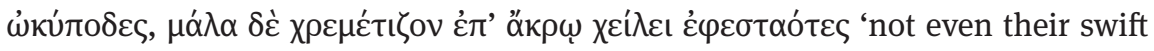
horses dared, they neighed, stopped next to the farthest edge' of a pit (Il.12.50).

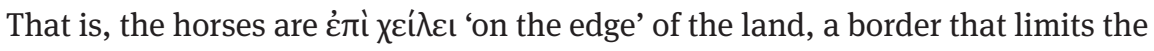
land and separates it from the pit. But the adjective ökроৎ is added to insist on it being 'right on the very edge', 'on the most extreme part of that border'. It can no longer surprise us that the preposition used in this and other examples is ćrí.

It would be interesting to explore how far in time this conceptual view can go back, comparing, from this new point of view, the forms apparently related to $\dot{\pi} \pi$ í in other languages, as well as any other reflection of it. As a first step, we can turn to a family of Latin terms to illustrate this conceptualization, since we observe traces of it in the evidence of terms such as extremus, which is just the superlative of exter/exterus, with the suffix *-ter, that is, 'which is in the outer part', cf. adv. extra 'outside', 'in the exterior'. However, Eng. extremity and extreme, as adjective and noun, and its equivalents in other modern languages are usually limited to the 1D and 2D scope. On the contrary, the compar. Lat. exterior 'which is farther out' is used in the modern languages, as adjective and noun, in the 3D scope. In fact, as a noun the exterior can designate the surface of an object or geometric body.

\subsection{Diachronic view}

As we have seen, the new system based on the use of the genitive to specify the superior location, with vertical orientation, had without doubt its origin in the need to solve ambiguities in PP with certain 3DL such as the ships, the altars or

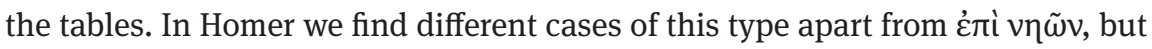
we find also the genitive in these cases that allows preserving the dative because they do not provoke ambiguity, which leads to the coexistence of '̇ंì $\chi \theta 0 v i$ and

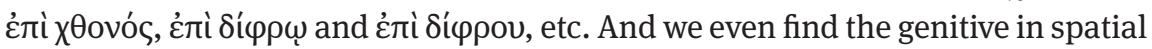
situations where there is no verticality but rather support, pressure or momentary contact produced by an impulse, where one could hope to find the dative

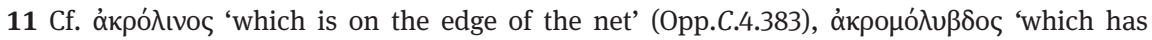
weights on the edges' $\lambda$ ívov in AP 6.5 (Phil.), Síktuov in AP 6.30 (Maced.), etc. 


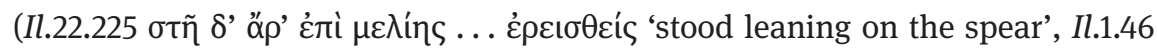

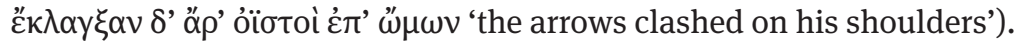

We also see how the construction with the genitive case is being increasingly used for all types of landmarks. The usage of the genitive in this cases tells us that orientation acquires more importance as a semantic category contained in the PP than dimensionality. Thus, it appears with 2DL that constitute or serve as limits

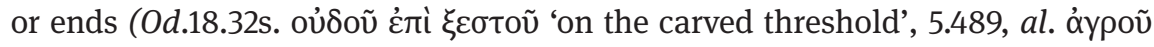

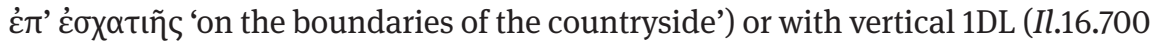

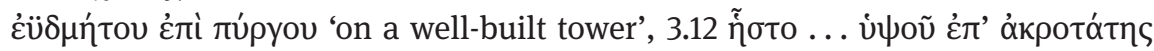
корטчп̃ऽ 'he was sitting on high, on the very topmost peak').

By the classical period, the diffusion of the genitive had advanced enormously, even reaching the uses without vertical localization (DGE s.u. Ėrí C I 4

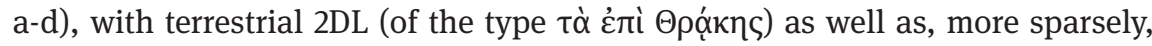

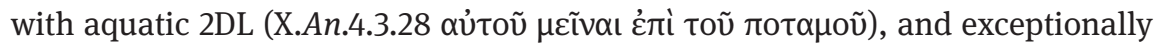

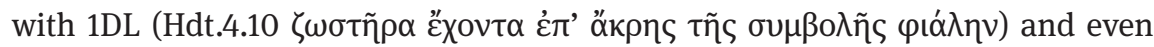

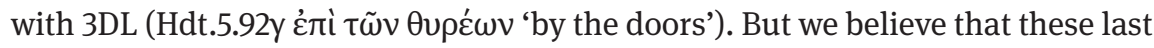
two, very isolated, examples should be understood as trials within the general process of expansion of the construction with the genitive, which invades not only the local uses typical of the dative, but also the temporal and the abstract uses. ${ }^{12}$ If they did not prosper it was, precisely, because they again introduced ambiguities in the system.

In a general diachronic view, we see how the use of żni with dative progressively loses ground against the genitive, which more and more broadens its uses with all types of landmarks and in different types of spatial relations. This enters into the general process of the disappearance of the dative in Greek, but it is also due in this particular case to the imposition of this new system. In the locative uses, this implies that $\dot{\varepsilon} \pi i$ will be used principally with genitive, indicating both

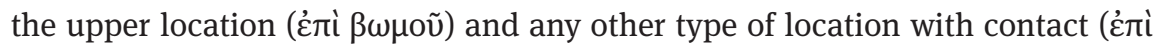

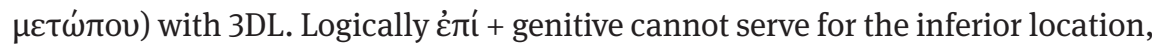
for which one must turn to vंtó or, if one wants to specify contact, to maintain the basic use with 3DL of $\dot{\varepsilon} \pi \dot{i}$ + dative. We can see it in a precious example of Eusebius of Caesarea (III/IV A.D.) following Alexander Polyhistor (I B.C.): in the description of Solomon's temple, he writes about the fabrication of some devices that made noise for the purpose of scaring away the birds (oppvea) 'so that they do

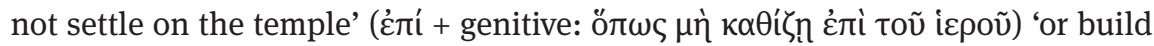

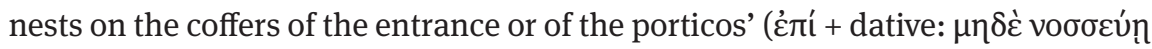

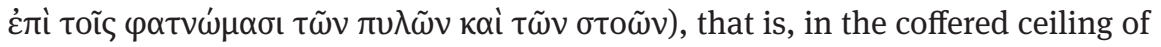

12 Cf. Rodríguez Somolinos (forthcoming). 
the lintels and the porticos, surfaces which are easily visible from the floor. Obviously, here we have an "under" orientation, and the use of the PP with dative, still in that time, preserves the original meaning of cं $\pi$ í with 3DL indicating the close contact between the nest and the lower surface of the ceiling to which it adheres. For the metaphorical lateral location, that is, for the meaning 3DL 2 'next to', the

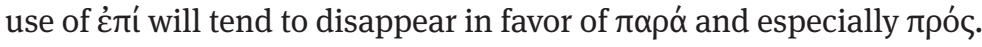

Also from very early $\dot{\varepsilon} \pi i ́$ + genitive assumes the uses with limited 2DL, where naturally it goes on to indicate the superior location, not on the ends (S.OT 1059, Hdt.1.17, Isoc.7.52, '̇ $\pi$ ' $\alpha y \rho \tilde{\omega} v$ 'in the fields'). It is also used with names of edges or

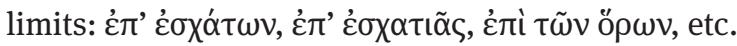

The use of the dative will be preserved in a wider form in the cases of 2DL and 1DL where less ambiguity is introduced and more usefulness is provided, which are:

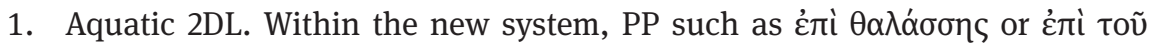

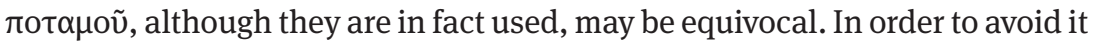
one may turn to another preposition, but the semantically closest one, $\pi \rho$ ó $_{\text {, }}$ indicates a different degree of proximity. That is the reason why the writers of

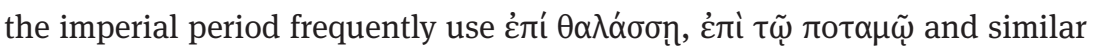
PP. Besides, in poets, we must take into account the influence of the earlier poetic tradition.

2. 1DL names of capes. This may be the most regular and permanent of all the uses with the dative, since we never find $\dot{\varepsilon} \pi i$ + genitive indicating the location in the edge of a cape, especially with a proper name. In ancient Greek

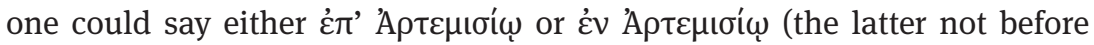
Plutarch), but never *'ं $\pi$ ' 'A $\rho \tau \varepsilon \mu$ бíov.

3. 1DL of vertically elevated elements (mountains, trees, etc). Given that this use is perfectly integrated within the general use of ' $\dot{\pi} \boldsymbol{i}$ + genitive, because of its orientation, there is no problem with using the genitive. Nonetheless, PP

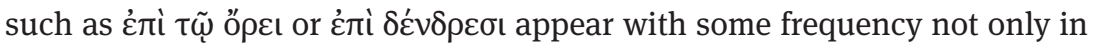
poets but also in prose writers of the imperial period, along with the increas-

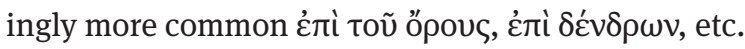

We believe that this overview may help clarify the confusing landscape of the locative uses of '̇ंí. The ideas presented here, arisen directly from the study of a large number of data, allow understanding of their anomalies according to their history, solving problems of interpretation of certain unclear spatial situations, and allowing, finally, to start from a single basic meaning of the preposition/ preverb, in order to deduce from it all the other local, temporal, and abstract meanings. 
Acknowledgments: This paper has been prepared within the Research Project Diccionario Griego-Español (Continuación) of the Spanish Ministerio de Economía y Competitividad (Ref. FFI2010-2036). I use the abbreviations of authors and works of the Diccionario Griego-Español, as well as its reference editions. All translations of Greek texts are mine, unless otherwise indicated.

\section{References}

Berenguer, J.A. (2000): Estudios sobre las partículas indoeuropeas con base consonántica y laringal. Madrid, C.S.I.C.

Chantraine, P. (1968): Dictionnaire Étymologique de la Langue Grecque. Paris, Klincksieck (n. ed. 2009).

Herskovists, A. (1986): Language and Spatial Cognition. An Interdisciplinary Study of the Prepositions in English. Cambridge, Cambridge University Press.

Herskovits, A. (1998): "Schematization”, in P. Olivier \& K.-P. Gapp (eds.): Representation and processing of spatial expressions. Mahwah, New Jersey, Lawrence Erlbaum Associates, pp. 141-153.

Luraghi, S. (2003): On the meaning of prepositions and cases: the expression of semantic roles in ancient greek. Ámsterdam, John Benjamins, 2003.

Morpurgo Davies, A. (1983): “Mycenaean and Greek prepositions: o-pi, e-pi, etc.”, in

A. Heubeck et alli (eds.), Res Mycenaeae. Akten des VII. Internationalesn Mykenologischen Colloquiums (Nürnberg, 6-10 April 1981), Göttingen, Vandenhoeck \& Ruprecht, pp. 287-310.

Radden, G. - Dirven, R. (2007): Cognitive English Grammar. Amsterdam, John Benjamins.

Rodríguez Somolinos, H. (2012): "Sobre ćmí + dativo. Usos locativos", in A. Cabedo \& P. Infante (eds.), Lingüística XL. El lingüista del siglo XXI. Madrid, Sociedad Española de Lingüística, pp. 217-223.

Rodríguez Somolinos, H. (forthcoming): "La preposición Ėmí en el Diccionario Griego-Español", in Actas del XIII Congreso Español de Estudios Clásicos. Madrid, Sociedad Española de Estudios Clásicos.

Ruijgh, C.J. (1994): “La préposition émí. Valeurs sémantiques et choix de cas”, in B. Jacquinod (ed.), Cas et prépositions en grec ancien. Contraintes syntaxiques et interprétations sémantiques. Saint-Étienne, Centre Jean-Palerne - Univ. de Saint-Étienne, pp. 133-148.

Talmy, L. (1983): “How Language Structures Space”, in H. Pick \& L. Acredolo (eds.), Spatial orientation. Theoory, research ad application. New York, Plenum Press, pp. 225-282.

Talmy, L. (2000): Toward a Cognitive Semantics. Cambridge, MA, MIT Press.

Van Laer, S. 1998: “Le préverbe ob- en latin: considérations sémantiques”, in B. García Hernández (ed.), Estudios de Lingüística Latina. Actas del IX Coloquio Internacional de Lingüística Latina. Madrid, Ediciones Clásicas, pp. 1043-1059.

Van Laer, S. (2010): La préverbation en latin. Étude des préverbes ad-, in-, ob- et per- dans la poésie républicaine et augustéenne. Brussels, Latomus.

Vandeloise, C. (1991): Spatial Prepositions: A Case Study from French. Chicago - London: University of Chicago Press. 